\title{
Erratum zu: Fachenglisch für BioTAs und BTAs
}

\section{Erratum zu: \\ U. Steiner, Fachenglisch für BioTAs und BTAs, https://doi.org/10.1007/978-3-662-60666-7_13}

Der auf S. 82 fälschlicherweise gesetzte Kommentar der Autorin „Habe ich Ihnen geschickt / Das arabische Wort für Chemie kommt hier rein“" wurde entfernt.

Die Zeilenangaben in den Vokabeltabellen auf S. 12, 22, 29 und 41 wurden entfernt.

Die aktualisierte Version dieses Buches finden Sie unter https://doi.org/10.1007/978-3-662-60666-7_1 https://doi.org/10.1007/978-3-662-60666-7_2 https://doi.org/10.1007/978-3-662-60666-7_3 https://doi.org/10.1007/978-3-662-60666-7_4 https://doi.org/10.1007/978-3-662-60666-7_5 https://doi.org/10.1007/978-3-662-60666-7_7 